\title{
Exploring Online Double Deviation Effect from Psychological Contract Violation, Emotion, and Power Perspectives
}

\author{
Yu-Hui Fang \\ Department of Accounting \\ Tamkang University \\ yhfang@mail.tku.edu.tw \\ Chao-Min Chiu* \\ Department of Information Management \\ National Sun Yat-sen University \\ cmchiu@mis.nsysu.edu.tw
}

\begin{abstract}
Service recovery is a critical moment of truth in retaining customers and reinforcing customer relationships, and has been considered as an "Achilles' heel" in online marketplaces. Poor service recoveries exacerbate the negative effects of the failure, producing a "double deviation" effect. The double deviation effect may arise from the seller's power misuse and then dissolve the buyer-seller relationship (e.g., violate consumer psychological contract), elicit consumer negative emotions which lead to customer coping behaviors. This study links the theories of psychological contract violation (PCV), emotion, and coping from the power perspective to investigate the double deviation scenario in online auction marketplaces. Two moderators (perceived power and perceived consumer empowerment) are considered in our proposed model. Data collected from 190 consumers of one auction website provide support for the proposed model. The results shed light on what constitutes the determinants of consumer judgments while facing double deviation scenario and how consumers react to and cope with it in online marketplaces. Finally, implications and limitations are discussed in the last part of this paper.
\end{abstract}

Keywords: Coping Behaviors, Emotions, Justice, Power, Psychological Contract Violation, Service Recovery.

\footnotetext{
${ }^{*}$ Corresponding author.
} 


\section{Introduction}

Service recovery is a critical moment of truth in retaining customers (Tax and Brown, 1998) and reinforcing customer relationships (Blodgett et al., 1997), and has been considered as an "Achilles' heel" in online marketplaces $^{1}$. Poor service recoveries exacerbate the negative effects of the failure, producing a "double deviation" effect (Bitner et al., 1990), a perceived inappropriate and/or inadequate response to failures in the service delivery system. Since online market is more mature and online consumers have more experience and needs than before, it is time for online sellers or retailers to focus on service recovery issue beyond merely ordertaking. Recent research in IS and ecommerce areas has began to investigate the issues of either online service recovery or online service failure (e.g., Kuo and Wu, 2012; Li et al., 2013). Specifically, as with any transaction mode, an online seller can exercise his/her power inappropriately in service recovery process without consumers' consent, against their will (Dwyer et al., 1987), and without fulfilling his/her obligations, which may lead to consumers' emotional and behavioral reactions. This implores the following research questions: 1)What constitutes the determinants of consumer judgments while facing double deviation scenario ; and 2) How consumers react to and cope with it in online marketplaces? Specifically, consumers are the primary service receivers and their subjective perceptions are the most relevant for predicting consumers' coping behaviors in response to the online double deviation scenario. To better understand the research questions, we refer to power perspective, which aims to explain unequal power between the exchange parties in the presence of online double deviation scenarios.

\footnotetext{
${ }^{1}$ Forrest.com,

http://www.forrester.com/Research/Document/Excer $\mathrm{pt} / 0,7211,40652,00 . \mathrm{html}$ [accessed on October 12, 2009]
}

While power perspective has primarily been investigated within the context of organizational relationships, it has been expanded to buyer-seller relationships within offline (Dwyer et al., 1987) and online marketplaces (Fang, 2012), typically viewing buyer as a powerless party and seller as the opposite one. The double deviation effect may arise from the seller's power misuse (e.g., refuse to refund) and then dissolve the buyer-seller relationship (Schneider and Brown, 1999. This can be conceived as a violation of the psychological contract between consumers and the seller. Under the assumption of triggers of psychological contract violation (PCV) may be rooted in the seller's failure to meet the obligations or promises regarding justice perceptions (Morrison and Robinson, 1997), we propose four injustice constructs (i.e., distributive, procedural, interpersonal, and informational injustice) that form PCV perception in assessing service recoveries. Moreover, PCV evokes negative emotion (e.g., anger and dissatisfaction) (Cullinane and Dundon, 2006), and this negative emotion is likely to be strong, especially for consumer in the vulnerable position (i.e., the initial service failure and the failed recovery) (Voorhees et al., 2006). Despite the important link between PCV and justice in double deviation effects, and the power asymmetry in online marketplaces; prior research on service recovery has been focusing on disconfirmation theory or justice theory.

In addition, negative emotions stemmed from the double deviation will motivate consumers to engage in various forms of emotion-focused coping behaviors such as negative word-of-mouth, boycotting, and exiting (DeWitt and Brady, 2003). Based on the theory of coping, consumers perform coping strategies in attempts to vent their emotions, restore the justice, or simple away from the problem (Barclay et al., 2005). Although a recent trend has suggested a shift from the seller to the consumer in online marketplaces (Rezabakhsh et al., 2006; Kucuk, 2008), there are only few attempts to analyze online consumer coping behaviors 
through the logic of power. Power perspective provides specific ways to analyze consumer coping behaviors, through consumer empowerment, which can be extended to and provide new insights to study consumer reactions to online double deviation effect. For example, how consumers exercise their power to achieve their goals (as described earlier) will be one interesting question to further explore.

Given the increased importance of service recovery in online marketplaces and the lack of empirical research on the double deviation effect in the information systems (IS) context, this study links the theories of PCV, emotions, and coping from the power perspective to fill the abovementioned knowledge gap. The contributions of this study include (1) introducing broader configurations of PCV to IS research, (2) an rich understanding of their specific associations with negative emotions, (3) validating the effect of negative emotions on consumers' coping behaviors, (4) exploring the abovementioned relationships and issues from power perspective, and (5) the provision of empirical support for the proposed relationships.

\section{Theoretical Framework and Research Hypotheses}

\section{The Double Deviation Effect}

Despite that service recovery-the process by which the seller attempts to identify and rectify service failures or quality problems (Fitzsimmons and Fitzsimmons, 2001)-has been widely touted, the exploration of the double deviation effect is still in its infancy. Past research on consumer evaluation of recovery efforts has adopted two theoretical perspectives including the disconfirmation model (McCollough et al., 2000) and the justice theory (Maxham and Netemeyer, 2002). The disconfirmation model suggested that customers compare perceived recovery performance to recovery expectations. Recovery performance that exceeds expectations is positively disconfirmed, whereas performance falls short of expectations is negatively disconfirmed, i.e., double deviation effect (McCollough et al., 2000). Alternatively, justice theory suggested justice components are the primary sources of customer evaluations to recovery encounters (Maxham and Netemeyer, 2002). Despite their advances to service recovery, there is still much to learn in this area because of most research conducts in the context of offline markets and concerns with the positive impacts and benefits only in effective service recovery. Recovery failure is one of the main reasons that drive customers away and may jeopardize seller profitability (McCollough et al., 2000). Hence, the double deviation effect deserves more than a passing notice, especially, in online marketplaces where the spatial and temporal separation between buyer and seller provides challenges (e.g., information asymmetry, the problems of opportunism and uncertainty) (Fang, 2012) for both parties regarding the double deviation issue.

\section{Psychological Contract Violations and Service Recovery}

The psychological contract refers to "an individual's belief regarding the terms and conditions of a reciprocal exchange agreement between the focal person and another party" (Rousseau, 1989). In other words, a psychological contract violation (PCV) occurs when the focal person perceives the other person has failed to fulfill his/her obligations or promises. The rationale for our applying PCV to online consumer judgment of the service recovery process is twofold. First, in online marketplaces consumer subjective perceptions dominate their behaviors (e.g., reactions) and decision making (Fang, 2012). The beliefs, implicit, or subjective natures of psychological contract (Conway and Briner, 2005) are predominantly derive from consumer subjective perception, representing the appropriateness of PCV concept in the service recovery process. Second, the perceived agreement, not actual agreement, is required for psychological contract (Conway and Briner, 2005). This feature of the psychological contract is 
compatible with our concerns regarding consumer assessment of the service recovery process. Pavlou and Gefen (2005) have provided the justification for this application by regarding PCV with an individual seller as a buyer's sensitivity of having being treated improperly. More notably, our proposed extension is consistent with Rousseau's (1989) call for research linking PCV to other theories and extending to elucidate other kinds of relationships such as buyer-seller relationships.

One widely accepted typology of psychological contract (PC)-transactional and relational $\mathrm{PC}$-is considered as the underlying constructs in this study. Transactional PC has a purely economic or materialistic focus and explicit performance terms. Such contracts are often short-time orientated, narrow in scope, and entail limited involvement by both parties (Rousseau, 1989). Relational PC, in contrast, is broader, open-ended, loosely specified, and subjective and implicitly understood by the parties (Conway and Briner, 2005; Rousseau, 1989). Although previous literature has mainly paid attention to the transactional nature of buyer-seller relationships in online transaction, online buyer-seller relationships can last for a long period of time in view of product warranties, product returns, and post-purchase service and support (Pavlou et al., 2007). Hence, the PC implicit in relationships are thoughtful constructs for understanding the nature of the interactions between sellers and buyers (Schneider and Bowen, 1999).

Furthermore, transactional and relational PC are parallel to two distinct service recovery philosophies. The first one is transactionfocused perspective of service recovery, directed to ensure consumer satisfaction at "the moment of truth" when the consumer interacts with the seller (Zeithaml and Bitner, 1996). Alternatively, the second one is more a relationship-focused view, this view considered service recovery as not only remedy specific instances of failure, but also refine the service delivery system such that future mistakes are prevented, consumer's overall perceptions of service quality are enhanced, and long-term relationships with loyal customers are assured (Brown et al., 1996). In short, transaction-focused view of service recovery suggests that service recovery is an alternative route to consumer satisfaction, whereas relationship-focused view emphasizes the significance of consistency and reliability in developing long-term customer relationships (Brown et al., 1996). The relationship-focused view can complete the functions of service recovery and is also consistent with the customer relationship management trend in marketing literature (Schneider and Bowen, 1999). According to the logic above, it is rational to link transactional and relational PCV to these two service recovery philosophies and apply them to explore the impact of failed recovery.

\section{Injustice Dimensions as Sources of Psychological Contract Violations}

Justice theory states three justice concepts as the significant sources of customer evaluations of service recovery encounters (Schoefer and Diamantopoulos, 2008).For example, feelings of violation may be affected by judgments relating to the recovery outcomes (distributive justice), the recovery procedures (procedural justice), and the quality of interpersonal treatment received from the seller (interactional justice) (Kickul et al., 2001). Justice is critical because consumer responses to injustice recoveries are inclined to be heated, emotional, and long lasting (Schneider and Bowen, 1999). Carr (2007) has asserted the consumer's concern not only with service quality but also with the evaluations of service fairness. Specifically, Rousseau (1989) has argued that PCV is a deeper experience of inequity. Injustice dimensions are useful perspectives to explain employees' reactions to different types of contract violations (Andersson, 1996). DelCampo (2007) also suggests more focus on the evaluation of fairness for future psychological contract research. Given that individuals' assessments of violation are affected by their perceptions of how fairly 
they were treated (Morrison and Robinson, 1997), this study regards Colquitt's (2001) four (in)justice dimensions-distributive, procedural, interpersonal, and informational injustice-as the building blocks of transactional and relational PCV in online double deviation effects.

Distributive justice refers to the extent on which consumers perceive they have been treated fairly with regard to the final recovery outcome (Maxham and Netemeyer, 2002). Distributive justice centers on fairness of outcomes (Adams, 1965), such as refunds, discount, correction of charges, repairs, replacements (Tax and Brown, 1998), or other forms of atonement offered to consumers (Maxham and Netemeyer, 2002), the enumeration of which are hallmarks of transactional contracts. It is logical to regard distributive injustice as source of transactional contracts. Apart from the justice of recovery outcome, consumers pay attention to the fairness of recovery procedures as well. Some scholars (Kelley et al., 1993) assert that it is often a seller's response to a failure (e.g., the unwillingness on the behalf of the seller to fulfill what was promised), rather than the failure itself, that triggers consumers' discontent (i.e., violation of consumer's relational contracts). This notion underscores the reneging cause of PCV (Morrison and Robinson, 1997) as well as the profound influence of interaction between buyers and sellers on the evaluation of service recovery (Maxham, and Netemeyer, 2002). For example, despite receiving full refunds to service failures (distributive justice), consumers perceive relational contract violations if the seller treats them with inconsistent policies (procedural injustice), in impolite manner (interpersonal injustice), and without thoroughly explanations regarding the recovery procedure (informational injustice).

Procedural justice is defined as the fairness of the policies and processes contributing to recovery outcomes embodying certain types of normatively acceptable principles (Carr, 2007). Procedural justice is important in exchanges involving conflict resolution, (e.g., recovery process) due to its ability to maintain a long-term relationship between exchanged parties (Maxham and Netemeyer, 2002; Seiders and Berry, 1998). Rather than merely focus on interactional justice, which has been largely discussed in service literature, we further explore two perspectives on interactional justiceinterpersonal and informational justice (Greenberg, 1993). Interpersonal justice captures the degree to which consumers are treated with politeness, dignity, and respect by sellers throughout the recovery process. Informational fairness is defined as providing information or knowledge about procedures that demonstrate regard for consumers' concerns (Carr, 2007). Interactional justice (i.e., interpersonal and informational justice) is primarily emphasized on the quality of the relationship between the exchange parties (O'Donohue et al., 2007), lying at the heart of service recovery (Schneider and Bowen, 1999). As Zemke and Bell (2000) stated, "Providing a full explanation of what happened and what will happen to fix the problem is critical" to service recovery process, denoting the significant features of procedural, interpersonal, and informational justice as well as those of relational contracts. Under the circumstance where procedural justice and interactional justice are relational component of the psychological contract (DelCampo, 2007; Shore and Tetrick, 1994), it is justified to consider procedural, interpersonal, and informational (in)justice as sources of relational contract.

\section{The Stimulus-Organism-Response Paradigm}

Stimulus-organism-response

(S-O-R) paradigm specifies mediating processes in an organism that transmit a stimulus to a response (Woodworth, 1928). Stimulus has been conceptualized as something that provokes action (Bagozzi, 1986). Organism refers to the internal processes and structures intervening between stimuli and the final responses (Bagozzi, 1986) including perceptual, physiological, feeling, and thinking activities. Response is tied with the 
psychological reactions such as behavioral reactions of individuals (Bagozzi, 1986). According to the $\mathrm{S}-\mathrm{O}-\mathrm{R}$ paradigm, transactional PCV and relational PCV (stimulus) may affect customers' emotions (organism), which in turn may influence the consumer's coping behaviors (response). Previous research (e.g., Fang, 2012) has applied the S-O-R paradigm to predict consumer behavior in online shopping settings and her findings have supported its applicability. Therefore, we applies S-O-R paradigm to link theories of $\mathrm{PCV}$, emotions, coping, then develop related hypotheses.

\section{Emotions}

Emotions have been conceptualized as individuals' reactions to an event or object, and it plays a significant role in human behaviors and thoughts (Lazarus, 1991). Emotions are particularly germane to service encounters since services are intangible and often imply dynamic interactions between the exchanged parties (Ashforth et al., 2008). As Lazarus and Cohen-Charash (2004) suggest that "the discrete emotions provide the most useful source of information about the fate of an adaptational process", we consider two types of negative emotionsanger and dissatisfaction-for our analysis. Anger, one of the most commonly experienced negative emotions in service encounters (McColl-Kennedy et al., 2009), arises when an individual experiences a personal slight or insult, demeaning offense, or harmful action (Lazarus, 1991). Dissatisfaction, in contrast, has been deemphasized historically. Some theorists depict dissatisfaction as "a negative term, related to anger, hatred, and disgust" (Storm and Storm, 1987); some demonstrate significant correlations between anger and dissatisfaction (Folkes et al., 1987); and some find distinct differences between anger and dissatisfaction (Bougie et al., 2003).

It has been acknowledged that anger and dissatisfaction enclose idiosyncratic behavior and behavioral tendencies (Bougie et al., 2003). For example, different appraisals lead to diverging emotions (Jones and Brinkert,
2008). Anger can signal disparate sources of messages, including discontent with an action, displeasure with treatment, or a violation of justice (Tavris, 1982). Dissatisfaction is an outcome-dependent emotion as it is related to the undesirability of an event, but not to its cause (Weiner, 1986). Turnley and Feldman (2000) have indicated that the experience of a psychological contract violation triggers dissatisfaction. Likewise, Kickul and Lester (2001) also found that satisfaction is negatively related to violations of the psychological contract. Along the same logic, given the outcome-dependent nature of dissatisfaction (Weiner, 1986), transactional PCV to be associated with dissatisfaction due to its outcome-orientation in terms of economic, tangible, short-term, and extrinsic features (Conway and Briner, 2005). Specifically, in view of its measure, i.e. distributive injustice, transactional PCV directly relates to the unfairness of the economic-focus outcome for the consumer as a consequence of the seller's failed recovery. Previous literature on justice has indicated that distributive injustice in rewards underlies dissatisfaction in the organizational context (Aquino et al., 1997). Consistent with past findings (Maxham and Netemeyer, 2002; Smith and Bolton, 2002), it is therefore straightforward to predict the positive impact of this transactional PCV (i.e., distributive injustice) on the consumer's dissatisfaction with the recovery failure. Thus, we propose:

\section{H1a: Transactional PCV is positively related to consumers' dissatisfaction in online double deviation scenarios.}

On the other hand, relational components of contracts are more emotionally perceived than transactional components and may trigger stronger emotions (anger) as well as dissatisfaction (Rousseau, 1989; Rousseau and Ho, 2000). Given the implicit promise of fair play by service, consumers except to be treated fairly but become angry when they perceive otherwise (Berry, 1995), signifying the importance of socio-emotional exchanges (i.e., relational contracts). In view 
of relational PCV, when either procedural or interactional injustice is perceived, relatively intense emotions are thought to emerge regardless of outcome favorability (Barclay et al., 2005). For example, the rude treatment (i.e., interactional injustice) of a customer during a service recovery encounters seems likely to elicit anger (Schoefer and Diamantopoulos, 2008) due to anger as a reaction to a personal slight or insult (Lazarus, 1991). Feelings of anger originate in the injustice that consumers perceived concerning with the policies and methods to rectify the recovery failure (procedural injustice) (Chebat and Slusarczyk, 2005). Thus, we propose:

\section{H1b: Relational PCV is positively related to consumers' dissatisfaction.}

\section{H1c: Relational PCV is positively related to consumers' anger.}

\section{Power in Online Marketplaces}

Power is conceived as the ability to affect others to achieve intended goals (French and Raven, 1959). We propose an extension of the lens of power to analyze online buyerseller relationship under the double deviation effect in online marketplaces. Given that the spatial and temporal separation between online buyer and seller aggravates the information asymmetry, fear of opportunism, and uncertainty (Pavlou et al., 2007); the power perspective provides new insights to illuminate the online buyer-seller relationship. For example, when a seller has resources that are desired by a buyer, an asymmetric power exists. The seller may engage in harmful opportunistic behaviors (e.g., refuse to give refunds), that is, power misuse. This is also evident by Pitt et al.'s (2002) argument that information incompleteness and information asymmetries do not provide conditions where individuals feel they have all the information to act, in a sense rendering them powerless. Besides, although resources arbitrated by sellers on which a buyer is dependent can take many forms, for our purpose it is useful to regard of their application as just or unjust sanctions (Dwyer et al., 1987).
In this study perceived power refers to the belief that events and outcomes are under one's own control, i.e., "a high expectancy for control of events" (Ross and Broh, 2000). This study intends to capture neither the factual power nor the true essence of power due to either a necessary differentiation between the factual power and the concrete exercise of power (Rezabkhsh et al., 2006) or an inexistence of the true power (DenegriKnott et al., 2006). Instead, we are devoted to the concept of potential power, i.e., we speak of power albeit a powerful actor hardly exercises his/her power (Rezabkhsh et al., 2006). People with power conviction believe that their behaviors can achieve desired outcomes, while people with powerlessness attribute success or failure to factors beyond their own control (Neal and Seeman, 1964). Although the moderator role of perceived power between PCV and negative emotion is not explicitly examined in the literature, there are indirect supports and empirical evidences for their effects. For example, Langer and Rodin (1976) have indicated that a subjective perception of control generates general happiness, and even health. Past research has shown that control over an unpleasant event ease negative affect (Hui and Bateson, 1991). In such sense, consumers who perceived high levels of power tend to accept the tangible outcomes (transactional PCV) and thus are less likely to feel dissatisfaction. This is because that high power consumers are quite certain that outcomes are under their control, not determined by forces external to themselves (Ross and Broh, 2000). In other words, the influence of transactional PCV on dissatisfaction declines as consumers' perceptions of power increased. On the other hand, consumers who perceive lower power convictions tend to express negative emotions to perceive changes in the relative power of consumers and sellers in response to the unfavorable outcomes (transactional PCV) (Kemper, 1987). Therefore, we propose: 


\section{H2a: Higher levels of perceived power reduce the influence of transact- tional PCV on dissatisfaction.}

Given that perceived power and control can emerge from a variety sources including economic resources, positions of authority, and respect from others (French and Raven, 1959), the perception of power can vary within the same individual depending on the situation. Relational contract is more complicated than transactional contract due to its intangible, social-emotional, and implicitly understood nature. With regard to relational PCV, we suggest that consumers who perceive higher power may get angry or dissatisfied more easily than those with powerless perceptions when their relational contracts are violated. This is because consumers with higher power perceptions tend to expect respect and fair treatments from sellers during consumer-seller interactions but generate negative emotions when they perceive otherwise (Chebat and Slusarczyk, 2005). That is, high power consumers pay more attention to the interaction procedure rather than the final outcome. Thus:

\section{$\mathrm{H} 2 \mathrm{~b}$ : The positive effect of relational PCV on dissatisfaction is greater with high perceived power than with low perceived power.}

\section{H2c: The positive effect of relational PCV on anger is greater with high perceived power than with low perceived power.}

\section{Consumer Coping Behaviors}

Specific emotions enclose distinctive behavior related to anger and dissatisfaction (Bougie et al., 2003). Oliver (1997) investigated customer dissatisfaction shows that customers would rather remain passive than active response while they are dissatisfied. Conversely, an intensely action such as complaining appears to be a rather common response to anger (McCollKennedy et al., 2009). We followed this logic to develop our hypotheses between emotions and coping behaviors. In addition, according to theory of coping (Lazarus and Folkman, 1984), coping behaviors refer to the cognitive and behavioral efforts that individuals make to master, tolerate or relieve stress and perceived adversity. Lazarus and Folkman (1984) distinguish two types of coping behaviors: problem-focused coping and emotion-focused coping. Problem-focused coping behaviors reflect adaptive behaviors directed at managing the situation causing the distress to resolve the problem. Emotion-focused coping behaviors are oriented toward managing emotional response to the problem to reducing negative emotions (e.g. anger). This study focuses on emotion-focused coping aspect because the impact of problem-focused coping on sellers has been mitigated through direct communication between consumers and sellers. To reflect the context of online marketplace, this study re-conceptualizes two coping behaviors-consumer switching behavior and destructive voice-to consistent with two emotion-focused coping methods (avoidance and emotional venting) (Duhachek, 2005).

\section{Consumer Switching Behaviors}

Consumer switching behaviors refer to consumers' voluntary termination of the relationship with a specific seller (Bougie et al., 2003). From emotion-focused coping perspective, switching behaviors signify the means of escaping from the stressful situation by avoidance (Duhachek, 2005). More specifically, the interactivity and market transparency features of Internet posit online consumers as more active roles and strengthen their switching opinions (i.e., deciding whom or where to transact with) (Rezabakhsh et al., 2006).

Given that dissatisfied customers have a feeling of unfulfillment, think about what they have sacrificed, and make a deliberate consideration of how to act (Bougie et al., 2003), they are less prone to invest energy to restore justice by retaliation (Grégoire and Fisher, 2008) but engage in switching behavior instead (Bougie et al., 2003). Given consumer switching behaviors as means for 
expressing consumers' economic preferences (Nunziato, 2000), consumers through Internet have instant access to alternative sellers to whom they can easily switch when dissatisfied (Rha and Widdows, 2002). Accordingly, we hypothesize the following:

H3a: Consumers' dissatisfaction is positively related to consumer switching behaviors in online double deviation scenarios.

\section{Destructive Voice}

This study regards destructive voice as attempts to vent negative emotions such as venting mechanisms in cyberspace. In extension of the destructive voice in online marketplaces, this study specifies electronic word-of-mouth (EWOM) and electronic boycott (E-Boycott) as sub-dimensions of destructive voice. The profusion of customer initiative websites (e.g., Yahoo! 2009) ${ }^{2} \mathrm{~F}$ implies that consumer retaliation and EWOM spreading have become predominant up to now. EWOM refers to customers' efforts to denigrate a seller for the product or service, but to a wider audience and in written form in cyberspace (Schoefer and Diamantopoulos, 2008). E-Boycott is "an attempt by one or more parties to achieve certain objectives by urging individual consumers to refrain from making selected purchases" (Friedman, 1985; p. 97) in the online marketplace.

Scholars have consistently demonstrated that customers' anger leads to destructive behaviors such as boycotting, negative word of mouth, and complaints to third parties (DeWitt and Brady, 2003). Not surprisely, the impact of such behaviors is more powerful online than offline because the boundless dialogue with unlimited Internet users strengthens EWOM and E-Boycott (Rezabakhsh et al., 2006). Customers who experience anger may go to considerable lengths to pay back or get even with the

\footnotetext{
${ }^{2}$ Yahoo!Directory,

http://dir.yahoo.com/Society_and_Culture/Issues_an d_Causes/Consumer_Advocacy and_Information

[Access date 10/19/2010]
}

seller that has mistreated them (Bougie et al., 2003), even when the dollar amount related to the issue is quite small (McColl-Kennedy et al., 2009). Accordingly, we hypothesize the following:

\section{H3b: Consumers' anger is positively related to destructive voice in online double deviation scenarios.}

Kucuk (2008) suggests consumer switching behavior is as a slow indicator of consumers' real intentions and expectations for online markets, whereas voice can be regarded as an early detection signal to take precautionary steps before switching leads harmful results to the seller. However, Keaveney (1995) has reported that $75 \%$ of consumers undertake destructive voice such as word-of-mouth communications regarding their switching incident in offline service encounters. Up to date the relationship between consumer switching behaviors and destructive voice in online marketplaces remains unclear. This study considers such issue from active and passive destructive view (Rousseau, 1995) as well as from the emotion-focused coping methods. Consumer switching behavior signifies passivedestructive and avoidance behavior, while destructive voice symbolizes activedestructive, retaliation, and emotion vending mechanism. Since unsatisfied consumers decide to undertake passive actions (switching) and to stay away from the problem, they are less likely to engage in active-destructive voice in response to their dissatisfaction. Therefore, we hypothesize the following:

H4: Consumers' switching behaviors is negatively related to destructive voice.

\section{Consumer Power in Online Market- places}

Recent research on consumer power has been applied to diverse contexts and relationships such as virtual teams, online support groups, buyers-suppliers or buyerscompanies relationships (AmichaiHamburger, 2008). However, notice that 
there seems to be lack of research and consensus about the consumer power, especially in the context of online markets. Given "the advantages of using Internet facilities to identify, reach, and persuade an audience to join an action" (Zureik and Mowshowitz, 2005), the Internet is possibly the most powerful instrument yet contrived to actualize consumer power. That is, online consumers are more powerful and demanding in their shopping expeditions than offline consumers (Koufaris, 2002), and may employ Internet technologies to exercise their power to cope with sellers' misbehaviors, i.e., coping behaviors. Accordingly, destructive voice can be regarded as a means of active consumer power, while consumer switching behavior as a passive consumer power.

Perceived consumer empowerment refers to a consumer's subjective experience that they have greater ability than before (i.e., the increased ability) to intentionally affect others (the offending seller) and prevent undesired outcomes (Wathieu et al., 2002). It is only the conception of increasing ability to influence others which evokes empowerment and empowerment may be experienced whether the ability/power actually increases or not. As consumers take charge of their online marketing environment, investing resources (time and efforts) in the control tools that are made accessible to them, they will presumably have raised outcomes favorable to them (Wathieu et al., 2002). From consumer power perspective, consumer switching behaviors denote a means for expressing an individual consumer's economic preferences in online markets (Nunziato, 2000), i.e., exercising consumers' sanction power to discipline a seller's misbehavior. Consumers who perceive higher empowerment have instant access to alternative sellers to whom they can easily switch through Internet when dissatisfied (Rha and Widdows, 2002). Thus, we propose the following:

H5a: The positive effect of dissatisfaction on consumer switching behaviors is greater with high perceived

\section{consumer empowerment than with low perceived consumer empowerment.}

Bougie (2003) stated angry customers may engage in destructive voice (Bougie et al., 2003), we propose the relationship is moderated by levels of perceived consumer empowerment. Destructive voice symbolizes a mechanism of regaining consumer power in the case of service failure. Robertson and Shaw (2006) have suggested the positive relationship between consumer empowerment and consumers' voice behaviors. Accordingly, angry consumers with higher perceptions of consumer empowerment will be inclined to perform destructive voice against an offending seller due to their active attempts at creating change. This is because empowered consumers are proposed to be active, to be self-initiating, and to be resilient to obstacles (Campbell and Martinko, 1998). Therefore, we hypothesize the following:

$\mathrm{H} 5 \mathrm{~b}$ : The positive effect of anger on destructive voice is greater with high perceived consumer empowerment than with low perceived consumer empowerment.

We also proposed that the perception of consumer empowerment may play a part in moderating the relationship between consumer switching behavior and destructive voice. As mentioned earlier, consumers who perceive higher empowerment are proposed to be active, high in persistence, likely to take challenge (Weary et al., 1989). In such case, consumers who undertake passive switching behaviors are less likely to embark on active destructive behaviors such as EWOM and EBoycott to struggle for change. Accordingly, the negative relationship between consumer switching behavior and destructive voice is greater when consumers perceive high empowerment than when they perceive low empowerment. Thus:

H5c: The negative effect of consumers' switching behaviors on destructive voice is greater with high perceived 


\section{consumer empowerment than with low perceived consumer empowerment.}

Overall, Figure 1 presents the proposed model. This study links the theories of PCV, emotion, and coping from the power perspective to investigate the double deviation effect in online auction marketplaces.

\section{Research Method}

\section{Measures}

All measurement items for this study's dominant constructs were adopted from existing validated measures (Appendix A). A pretest was conducted using 5 IS experts and 12 graduate students with online shopping experience to assess its logical consistencies, ease of understanding, sequence of items, and contextual relevance. Then, a pilot study with 150 customers of the target auction website was also conducted to assess the measurement properties of the final items. Note that, according to the suggestions from IS experts and our respondents, three items of switching behavior are relatively tended to reflect the meaning of switching intention rather than switching behavior. Therefore, these three items have been dropped during the procedure of the pretest and the pilot study.

\section{Survey Administration}

The research hypotheses were tested with data collected from 190 customers in YahooKimo's online auction website-one of the largest online auction markets in Taiwan. A banner with a hyperlink connecting to our Web survey was published on a number of bulletin board systems (BBS), and chat rooms, and individuals with online auction and service recovery experiences were cordially invited to support this survey. The Web survey lasted for 6 weeks and yielded a total of 190 complete and valid responses for data analysis. Table 1 presents the demographic information of the respondents.

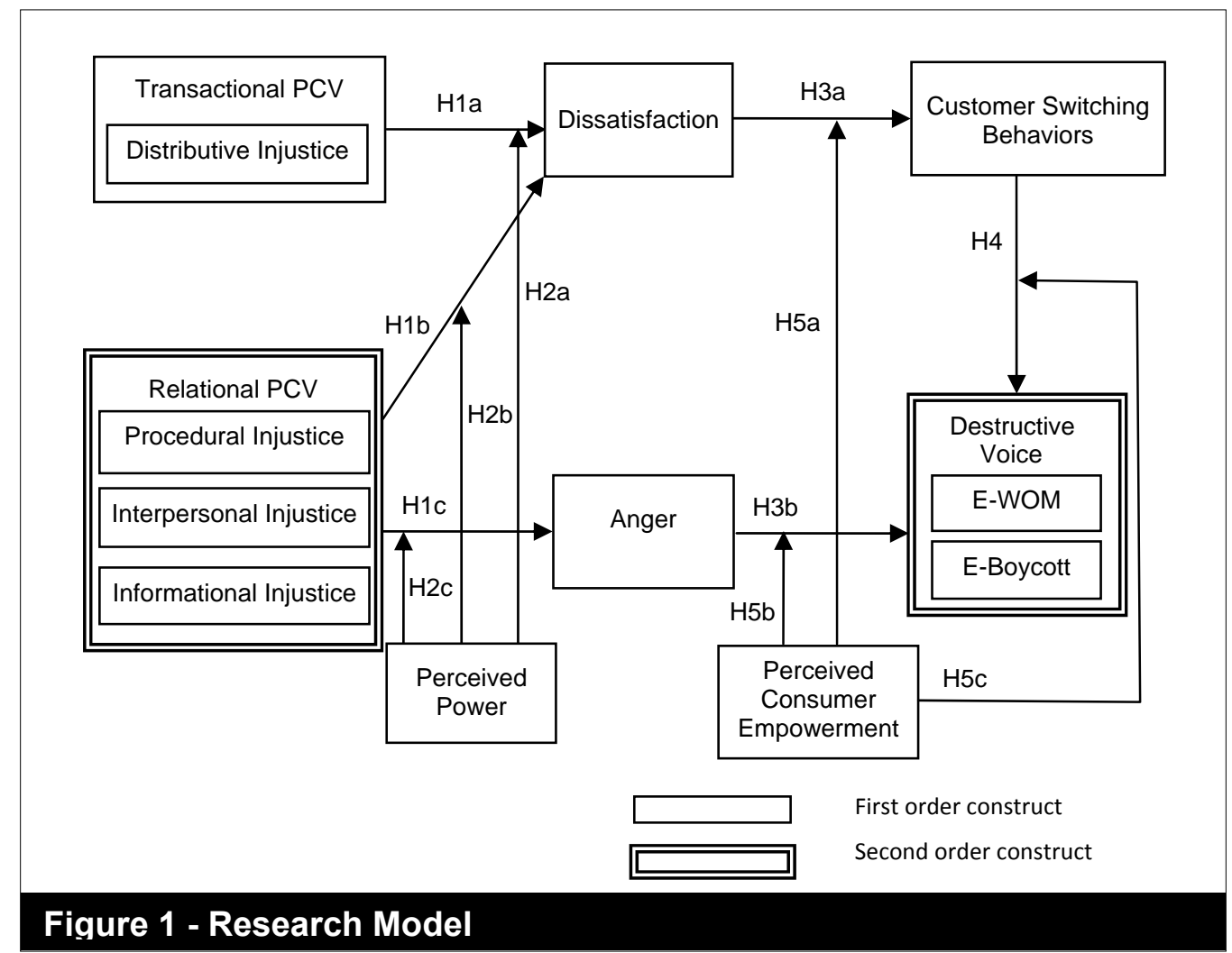




\begin{tabular}{|c|c|c|c|c|c|c|c|}
\hline Measure & Items & Freq. & $\%$ & Measure & Items & Freq. & $\%$ \\
\hline Gender & Male & 80 & 42 & Gender & Female & 110 & 58 \\
\hline Age & $\begin{array}{c}<20 \\
20-24 \\
25-29 \\
30 \sim\end{array}$ & $\begin{array}{c}6 \\
78 \\
76 \\
30\end{array}$ & $\begin{array}{c}3.2 \\
41.1 \\
40.0 \\
15.7\end{array}$ & Education & $\begin{array}{l}\text { High school } \\
\text { College \& } \\
\text { University } \\
\text { Graduate } \\
\text { school }\end{array}$ & $\begin{array}{c}6 \\
123 \\
61\end{array}$ & $\begin{array}{c}3.1 \\
64.7 \\
\\
32.2\end{array}$ \\
\hline $\begin{array}{l}\text { Online } \\
\text { Shopping } \\
\text { Experience } \\
\text { (in years) }\end{array}$ & $\begin{array}{l}1-2 \\
3-4 \\
5-6 \\
7 \sim\end{array}$ & $\begin{array}{l}17 \\
60 \\
65 \\
48\end{array}$ & $\begin{array}{r}8.9 \\
31.6 \\
34.2 \\
25.3\end{array}$ & \begin{tabular}{|l|} 
Yahoo \\
Auction \\
Shopping \\
Experience \\
(times in one \\
year)
\end{tabular} & $\begin{array}{l}1 \\
2-3 \\
4-5 \\
6 \sim\end{array}$ & $\begin{array}{c}9 \\
38 \\
37 \\
106\end{array}$ & $\begin{array}{c}4.7 \\
20.0 \\
19.5 \\
55.8\end{array}$ \\
\hline
\end{tabular}

\section{Data Analysis}

For data analysis, we utilized a two-step approach as recommended by Anderson and Gerbing (1988), involving the analysis of the measurement model and testing the structural relationships among the latent constructs. PLS (partial least squares) was used to evaluate both the measurement model and the structural model, because it allowed the latent constructs in our data to be modeled as formative or reflective indicators. PLS places minimal restrictions on measurement scales, sample size and residual distribution (Chin et al., 2003).

\section{Measurement Model}

Two second-order constructs (relational PCV and destructive voice) were approximated using repeated indicators, as suggested by Chin et al. (2003). The adequacy of the measurement model was evaluated for reliability, convergent validity, and discriminant validity. Reliability was assessed using composite reliability values. Table 2 shows that all the values were exceeded the commonly acceptable level of 0.7 . The convergent validity of the scales was assessed by two criteria (Fornell and Larcker, 1981): (1) all indicator loadings should be significant and exceed 0.7 ; (2) the average variance extracted (AVE) for each construct should exceed the measurement error variance for that construct (i.e., AVE should exceed 0.50). All items exhibited a loading greater than 0.7 on their respective constructs, and all the AVEs ranged from 0.73 to 0.91 (Table 2). Thus, both conditions for convergent validity were satisfied.

Discriminant validity is considered good if three criteria are met. First, the loading of each item on its assigned construct should be larger than its loading on any other construct (Chin, 1998). Second, the correlations among all constructs should be all well below the 0.85 threshold (Kline, 1998), suggesting that all constructs are distinct from each other. Third, the square root of the AVE of a construct should be greater than the correlation between the construct and the other constructs in the model (Fornell and Larcker, 1981). As shown in Table 3, all criteria are clearly met, demonstrating sufficient construct validity of the scales. 


Table 2- Descriptive Statistics for the Constructs
\begin{tabular}{|l|c|c|c|c|}
\hline \multicolumn{1}{|c|}{ Constructs } & Items & $\begin{array}{c}\text { Composite } \\
\text { Reliability }\end{array}$ & Mean (STD) & AVE \\
\hline Distributive Injustice (DJ) & 4 & 0.94 & $3.83(1.45)$ & 0.79 \\
\hline Informational Injustice (IFJ) & 4 & 0.95 & $3.43(1.48)$ & 0.82 \\
\hline Interpersonal Injustice (IPJ) & 4 & 0.96 & $3.10(1.39)$ & 0.85 \\
\hline Procedural Injustice (PJ) & 4 & 0.92 & $3.51(1.42)$ & 0.73 \\
\hline Perceived Power (PP) & 3 & 0.93 & $3.70(1.64)$ & 0.82 \\
\hline Anger (ANG) & 3 & 0.97 & $3.84(1.58)$ & 0.91 \\
\hline Dissatisfaction (DIS) & 3 & 0.89 & $4.25(1.49)$ & 0.73 \\
\hline Perceived Consumer Empowerment (PCE) & 4 & 0.92 & $3.29(1.27)$ & 0.74 \\
\hline Consumer Switching Behaviors (SWT) & 5 & 0.98 & $3.70(1.58)$ & 0.89 \\
\hline Electronic Word-of-mouth (WOM) & 4 & 0.92 & $4.82(1.51)$ & 0.75 \\
\hline Electronic Boycott (EBO) & 5 & 0.97 & $3.71(1.58)$ & 0.87 \\
\hline
\end{tabular}

\begin{tabular}{|c|c|c|c|c|c|c|c|c|c|c|c|}
\hline & ANG & EBO & PCE & DIS & DJ & IFJ & IPJ & PJ & PP & SWT & WOM \\
\hline ANG & 0.95 & & & & & & & & & & \\
\hline EBO & 0.25 & 0.93 & & & & & & & & & \\
\hline PCE & 0.20 & -0.24 & 0.86 & & & & & & & & \\
\hline DIS & 0.73 & 0.12 & -0.17 & 0.85 & & & & & & & \\
\hline DJ & 0.47 & -0.04 & -0.28 & 0.57 & 0.89 & & & & & & \\
\hline IFJ & 0.51 & -0.02 & -0.35 & 0.58 & 0.69 & 0.90 & & & & & \\
\hline IPJ & 0.53 & 0.09 & -0.28 & 0.57 & 0.63 & 0.76 & 0.92 & & & & \\
\hline PJ & 0.56 & 0.01 & -0.35 & 0.60 & 0.74 & 0.76 & 0.74 & 0.86 & & & \\
\hline PP & -0.36 & 0.10 & 0.29 & -0.38 & -0.27 & -0.17 & -0.15 & -0.20 & 0.88 & & \\
\hline SWT & 0.28 & -0.15 & -0.31 & 0.34 & 0.56 & 0.49 & 0.49 & 0.57 & -0.03 & 0.94 & \\
\hline WOM & 0.21 & 0.66 & 0.19 & 0.07 & 0.03 & 0.11 & 0.13 & 0.04 & 0.01 & -0.09 & 0.86 \\
\hline \multicolumn{12}{|l|}{ Note: } \\
\hline \multicolumn{12}{|c|}{ 1. The diagonal elements (in bold) represent the square root of the AVE. } \\
\hline \multicolumn{12}{|c|}{$\begin{array}{l}\text { 2. ANG = Anger; EBO= Electronic Boycott; PCE = Perceived Consumer Empowerment; } \\
\text { DIS = Dissatisfaction; } \mathrm{DJ}=\text { Distributive Injustice; IFJ = Informational Injustice; } \\
\text { IPJ = Interpersonal Injustice; PJ = Procedural Injustice; PP = Perceived Power; } \\
\text { SWT = Consumer Switching Behaviors; WOM = Electronic Word-of-mouth. }\end{array}$} \\
\hline
\end{tabular}


The correlation between three components of relational PCV (i.e. informational injustice, interpersonal injustice and procedural injustice) is relatively high $(r=0.74 \sim 0.76)$, a phenomenon also observed in the work by Fang and Chiu (2010) $(r=0.76)$. By operationalizing the three components of relational PCV as first-order indicators, we would overcome the problem that the three injustice variables are highly correlated and potentially non-discriminant; since formative constructs help determine whether any of the first-order constructs needs to be omitted due to high correlations. Therefore we conclude that the scales should have sufficient construct validity.

\section{Structural Model}

In PLS analysis, examining the structural paths and the R-square scores of endogenous variables assesses the explanatory power of a structural model. Figure 1 shows the results of structural path analysis. All paths exhibited a P-value less than 0.05 . The significance of all paths was assessed with 500 bootstrap runs. Overall, except for $\mathrm{H} 5 \mathrm{a}$, all of the hypotheses were supported, and the base model accounted for $18 \%$ of the variance for customer switching behaviors and 18\% for destructive voice (Figure 2).

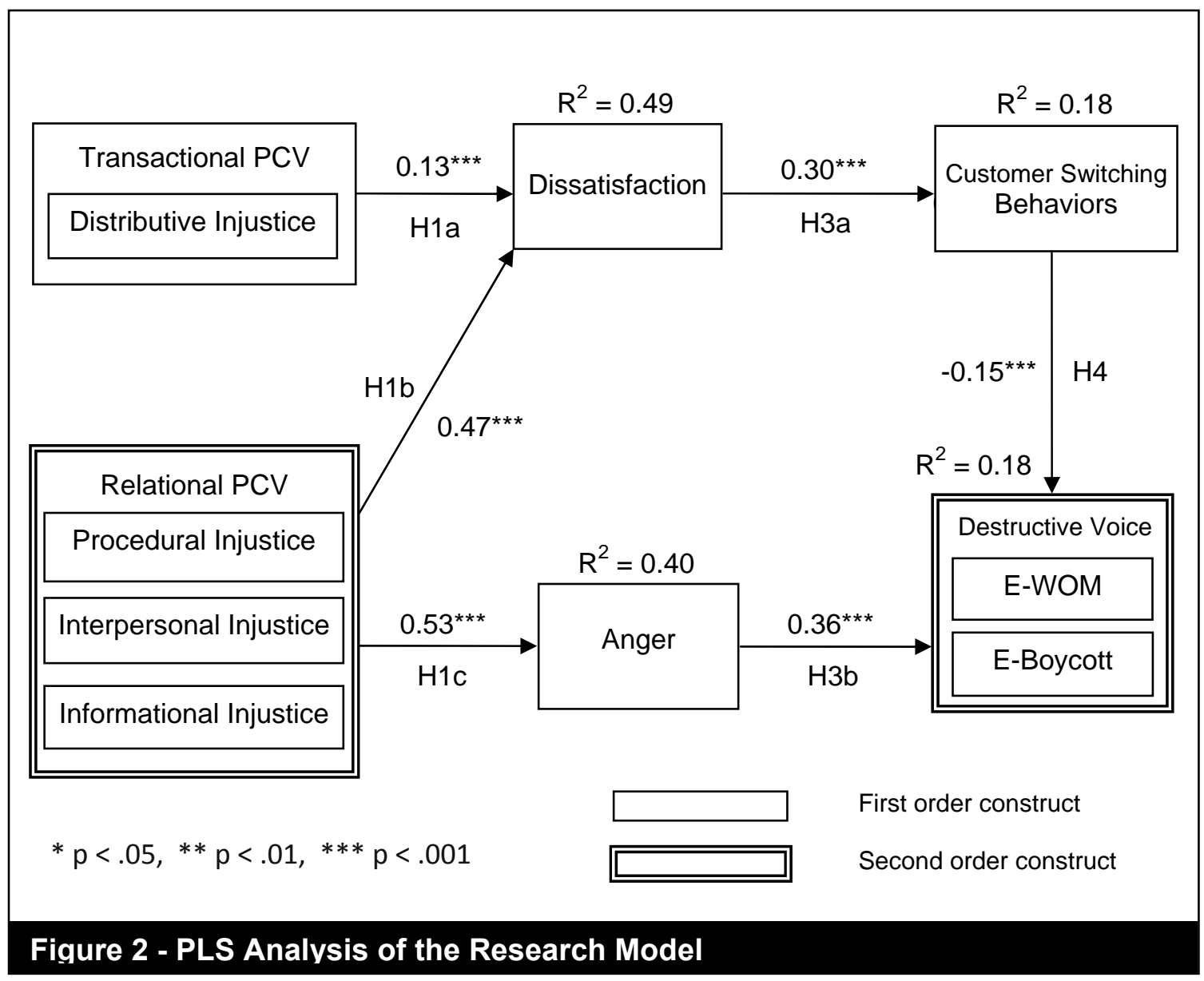


In addition, $\mathrm{H} 2 \mathrm{a}, \mathrm{H} 2 \mathrm{~b}$, and $\mathrm{H} 2 \mathrm{c}$ were tested by statistically comparing the path coefficients from PCV to negative emotions in the structural model for high perceived power with the corresponding path coefficients for low perceived power. Because perceived power was not a categorical variable, the groups were divided into high perceived power and low perceived power groups using the median (Baron and Kenny, 1986). Perceived power was divided by the median of the sum of the four perceived power items. The statistical comparison was conducted using Keil et al.'s (2000) procedure. Results (Table 4) indicate that for consumers perceiving a lower power in online double deviation effect, relational
PCV has a smaller effect on dissatisfaction $(B=0.34)$ than those perceiving a higher power $(B=0.705)$, which supports Hypothesis $2 b(t=54.82, p<0.001)$. Similar result for the moderating effect between relationship PCV and anger, which supports Hypothesis $2 c(t=13.64, p<0.001)$. Results also indicate that significant differences between transactional PCV and dissatisfaction $(\mathrm{H} 2 \mathrm{a})$ between high and lower perceived power groups $(\mathrm{t}=51.07, \mathrm{p}<$ 0.001). The same procedures were applied to test moderating effects for $\mathrm{H} 5 \mathrm{a}, \mathrm{H} 5 \mathrm{~b}$, and H5c. Table 5 presents the results of moderating effect testing for perceived consumer empowerment, thus supporting $\mathrm{H} 5 \mathrm{~b}$ and $\mathrm{H} 5 \mathrm{c}$.

\begin{tabular}{|c|c|c|c|c|c|}
\hline Path & High PP $(\beta)$ & Low PP $(\beta)$ & Difference & $t$-Statistics & Results \\
\hline $\begin{array}{l}\text { Transactional PCV } \\
\rightarrow \text { Dissatisfaction }\end{array}$ & -0.007 & $0.343^{\star \star \star}$ & -0.35 & $51.07^{\star * *}$ & $\begin{array}{c}\mathrm{H} 2 \mathrm{a}: \\
\text { Supported }\end{array}$ \\
\hline $\begin{array}{l}\text { Relational PCV } \rightarrow \\
\text { Dissatisfaction }\end{array}$ & $0.705^{\star \star *}$ & $0.340^{\star * *}$ & 0.365 & $54.82^{\star \star \star}$ & $\begin{array}{c}\text { H2b: } \\
\text { Supported }\end{array}$ \\
\hline $\begin{array}{l}\text { Relational } \mathrm{PCV} \rightarrow \\
\text { Anger }\end{array}$ & $0.616^{\star \star \star}$ & 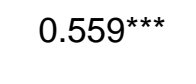 & 0.057 & $13.64^{\star \star \star}$ & $\begin{array}{c}\text { H2c: } \\
\text { Supported }\end{array}$ \\
\hline
\end{tabular}

Table 5 - Path Coefficients and the Results of Moderating Effect Testing for Perceived Consumer Empowerment (PCE)

\begin{tabular}{|l|c|c|c|c|c|}
\hline Path & High PP $(\boldsymbol{\beta})$ & Low PP $(\boldsymbol{\beta})$ & Difference & $\boldsymbol{t}$-Statistics & Results \\
\hline $\begin{array}{l}\text { Dissatisfaction } \rightarrow \\
\text { Switching }\end{array}$ & $0.329^{\star \star \star}$ & $0.320^{\star \star \star}$ & 0.009 & 1.55 & $\begin{array}{l}\text { H5a: Not } \\
\text { supported }\end{array}$ \\
\hline $\begin{array}{l}\text { Anger } \\
\text { Destructive Voice }\end{array}$ & $0.385^{\star \star \star}$ & $0.236^{\star \star *}$ & 0.149 & $25.28^{\star \star \star}$ & $\begin{array}{c}\text { H5b: } \\
\text { Supported }\end{array}$ \\
\hline $\begin{array}{l}\text { Switching } \rightarrow \\
\text { Destructive Voice }\end{array}$ & $-0.127^{\star \star}$ & $-0.219^{\star \star *}$ & 0.092 & $13.23^{\star \star *}$ & $\begin{array}{c}\text { H5c: } \\
\text { Supported }\end{array}$ \\
\hline
\end{tabular}




\section{Discussion and Implications}

This paper aims to shed light on the phenomenon of consumers' coping behaviors in response to their distinct negative emotions in online double deviation effects. This study contributes to our understanding of the effects of transactionalrelational PCVs on distinct emotional and behavioral responses. Overall, drawing from the power perspective, the study links the theories of PCV, emotions, and coping to develop and empirically test a model that explains consumers' coping behaviors toward the double deviation effect in online auctions.

\section{Key Findings}

The results support all the expected relationships among $\mathrm{PCV}$, emotions and coping behaviors in online auctions. The study has several key findings: First, it introduces the concept of PCV in double deviation effects in online auctions and identifies its underlying sources (i.e., injustice dimensions). Second, it provides a rich view of the online buyer-seller relationships by extending transactional and relational $\mathrm{PCV}$, which had previously been ignored in the literature. Using both transactional and relational PCV to explore their relationships with different negative emotions, the results support the hypothesized impact of distinct PCV on dissatisfaction and anger (Figure 2). Furthermore, we performed additional PLS analyses, which indicated that the path coefficient of transactional PCV increased from $0.13(t=2.79, p<0.001)$ to $0.49(t=$ $12.85, p<0.001$ ) by simply removing the relationship between relational PCV and dissatisfaction from the model. In other words, when including relational PCV as a predictor of dissatisfaction in the model, the direct effect of transactional PCV on dissatisfaction significantly decreased. It could thus be that the impact of transactional PCV was suppressed by relational PCV. Accordingly, this finding implies that when the impact of relational PCV is taken into account, consumers put more emphasis on relationship between consumers and sellers than on recovery outcomes when evaluating the feeling of dissatisfaction.

Third, it validates that perceived power negatively moderated the influence of transactional PCV on dissatisfaction $(\mathrm{H} 2 \mathrm{a})$ and positively moderated the influence of relational PCV on dissatisfaction and anger $(\mathrm{H} 2 \mathrm{~b}$ and $\mathrm{H} 2 \mathrm{c})$. Specifically, the importance of transactional PCV reduced as a predictor of dissatisfaction when power perceptions increased. That is, the effect of transactional PCV on dissatisfaction is highly significant in low perceived power group $(\beta=0.343, p<$ 0.001 ) but not in high perceived power group $(\beta=-0.007, p>0.05)$ (Table 4). Interestingly, the direction of the relationship between transactional PCV and dissatisfaction is changed from positive to negative, i.e., a negative suppression effect. A negative suppression effect reflects "a change in the direction (positive or negative) of the relationship between an independent variable and a dependent variable when a third factor (the suppressor) is controlled" (Mavor et al., 2009). The effect of transactional PCV on dissatisfaction meets the criterion for negative suppression because the zero-order correlation between transactional PCV and dissatisfaction is positive, but the beta coefficient of transactional PCV on dissatisfaction becomes negative when perceived power is controlled.

Fourth, it tests and supports the direct impact of dissatisfaction on consumer switching behavior $(\beta=0.30)$ and that of anger on destructive voice $(\beta=0.36)$ which is consistent with previous research (Grégoire and Fisher, 2008). Further analysis between dissatisfaction and destructive voice reveals the insignificant linkage $(\beta=-0.12 ; p>0.05)$. This result confirms Grégoire and Fisher (2008)'s argument that dissatisfied customers are less likely to invest energy to restore justice by retaliation (destructive voice in this study. Our results further support the indirectly 
negative effect of dissatisfaction on destructive voice through consumer switching behavior (Figure 2). Likewise, further analysis shows that anger does not directly affect switching behaviors $(\beta=0.04$; $p>0.05)$. A possible explanation for the insignificant relationship is that consumer responses in this study were cross-sectional, and thus did not present an opportunity to examine the actual switching behavior. Although the result between anger and switching behavior is different from that of Bougie et al. (2003), it is consistent with other studies (e.g., Roseman et al., 1994) that dissatisfied customers cope with passive behaviors whereas angry customers generally voice and complain.

Finally, our finding not only supports the positive moderating effect of perceived consumer empowerment between anger and destructive voice $(\mathrm{H} 5 \mathrm{~b})$ but also that between consumer switching behaviors and destructive voice. The importance of switching behavior increased as a predictor of destructive voice when consumer empowerment thoughts increased.

\section{Implications for Theory}

Building on research that examines PCV in online marketplace (Pavlou and Gefen, 2005), this research makes the further step by conceptualizing PCV based on the transaction-relational typology to shed light on online double deviation effects. Given that relationship is central to service and all kinds of buyer-seller dealings, the integration of the relational $\mathrm{PCV}$ results in a more descriptive model that better explains the interactions between buyers and sellers especially for the online double deviation effect. This is also consistent with relationship-focused view of service recovery literature (Schneider and Bowen, 1999). Our further analysis results regarding the impacts of transactional and relational PCV on dissatisfaction suggest that the impact of transactional PCV was suppressed by relational PCV. When both PCVs are considered concurrently, consumers put more weight on buyer-sellers relationship than merely on recovery outcomes when evaluating the feeling of dissatisfaction. Accordingly, this study extends the boundary of PCV research from employer relationships to buyer-seller relationships in the double deviation effect in online marketplaces.

Although most studies emphasize beneficial/positive behaviors (e.g., consumer retention, repurchase behaviors) rather than detrimental/negative behaviors (e.g., switching behaviors, destructive voice), it is evident that factors and relationships that predict positive outcomes may be asymmetrical with those that stimulate negative outcomes (Keaveney, 1995). This study makes contributions to uncover whether there is theoretical and empirical reason to determine the distinctive antecedents of anger and dissatisfaction and to assess how they differentially drive consumers' behaviors the electronic commerce is eventually concerned with. This study shows that negative emotions remain powerful, deeply affecting detrimental human behaviors, despite in today's IT-enabled environments where Internet features strengthen individuals' activities regardless of geographical and temporal limitations. This is compatible with Ortiz de Guinea and Markus's (2009) notion regarding the superordinate role of emotions in driving human behaviors. Our results agree with the recent trend on emotion research (e.g., Bouie et al., 2003; Grégoire and Fisher, 2008), demonstrating the significant effect of anger on destructive voice and that of dissatisfaction on switching.

Regarding detrimental/negative behaviors, although negative WOM has been the target of previous work (e.g., Anderson, 1998), Eboycott is relatively new and has hitherto received relatively little attention in today's IT-enable environments. We believe that the potential for online consumers to conduct destructive voice deserves special attention because the advent of Internet technology makes EWOM and E-boycott more convenient and accessible (e.g., Rezabakhsh et al. 2006). Complaint websites, instance message, consumer 
weblogs, and the recent phenomena of social networking (i.e., Facebook, Plurk) and user-created video sites (i.e., YouTube) have empowered online consumers, and these new online behaviors need to be better explored in the double deviation encounters.

Albeit that power asymmetry does exist between buyers and sellers in online marketplaces, limited attention has been paid to such issue. Existing research on customer assessment of recovery efforts has predominately focused on theories of disconfirmation (McCollough et al., 2000) and justice (Schoefer and Diamantopoulos, 2008); instead, this study analyzes such matter from power perspective and believes that the alternative view of power may shed new light on our context. Having shown the moderating role of perceived power between relational PCV and anger and dissatisfaction, this study suggests that understanding the power notion in online customer-seller relationships is an interesting issue for $\mathrm{C} 2 \mathrm{C}$ e-commerce research. It is because that online customers desire more control and power during the interactions with sellers especially in the service encounters (Rust and Kannan, 2003). In such sense, this study adds to the literature by presenting that consumers with higher perception of power tend to aggravate their anger and dissatisfaction conducted by relational PCV. Another major finding of the study is the moderating role of perceived consumer empowerment. It is important to search for moderating variables that turn simple main effects into more insightful conditional relationships (Featherman and Fuller, 2003). Evidence presented suggests that a deeper understanding of anger and potential coping behaviors is possible when interactions are taken into consideration. Furthermore, drawn from consumer empowerment perspective, this study suggests that angry customers may straightforwardly engage in destructive voice as a response to anger when they perceive high levels of consumer empowerment.

\section{Implications for Practice}

In this research, findings suggest that dissatisfaction in general does not generate a sufficient drive to voice, whereas anger serves to discourage online sellers from doing what elicits the anger or to remedy the failed service and recoveries. Given that angry customers have already recognized who or what should hold accountable for the failure (Folkes et al., 1987), they are now armed with powerful Internet technologies and take the advantages of IT-enabled environments (e.g., weblog, instance message) to raise their voice loudly and powerfully. For example, half of all the purchases that US consumers made in 2006 were affected by online sources mostly run by other users rather than by any specific firms (Marketing Management, 2007). Not surprisingly, these online behaviors such as EWOM and E-Boycott are destined to attract attentions from online sellers due to the impact on sellers' sales and reputations. Additionally, these findings support the intuitive notion that online sellers should attempt to prevent customers from getting angry and response to customers' complaining with extra care. On the other hand, having showing that dissatisfaction is a significant predictor of switching, this finding suggests that simply failed recovery outcomes may be sufficient reasons for consumers to switch due to the information ubiquity, reach, and interactivity traits of Internet. Seeing that most dissatisfied consumers in general do not bother to complain, sellers may lose opportunities to obtain consumer feedback, remedy the failure, and lose their business. This is best described by Huefner and Hunt (2000, pp. 77-78), "Exit, while it may imply a problem, does nothing to identify the nature of the problem itself. Voice is clearly more desirable because it allows identification of the problem where exit leaves a mystery."

However, it would be especially unfortunate for online sellers to interpret these above results merely from the negative side. We suggest that there may be a silver lining to a dark cloud in some cases. In this sense, that 
silver lining takes the form of perhaps positive benefits for online sellers that ensue from consumers' destructive voice. Such an argument at first glance may seem illogical, but it is not without theoretical foundation. In essence, examining phenomena such as the darker side of consumers' destructive voice to disclose different or alternative explanations is a sociological enterprise (Anderson and Taylor, 2005). For example, the recent contention of Barlow and Møller (2009)_translating customers' complaint into valuable pieces of feedback that can be applied to improve a seller's servicessuggests that marketing management is very sensitive to this issue. Therefore, it is critical for online sellers to learn and develop effective strategies to deal with angry customers. For example, applying the business models derived from service science, which view consumers not just as simple buyers but also as members who understand society's value systems and act responsibly (Kucuk, 2008) can create the opportunity for win-win situations.

Furthermore, online consumers who raise their voice can be conceptualized as "members rather than customers" (Nunziato, 2000). In such sense, consumer destructive voice is not just a preference-expressing mechanism on the Internet, but also a way for responsible and ethical individuals dedicated to society's collective value system to express themselves. That is, exerting consumer power to drive misbehaving sellers away from the specific online market. Accordingly, two suggestions for auction website providers/managers are also provided as following: First, these service providers (such as Yahoo-Kimo) can empower consumers through providing more convenient platforms and options for consumers' free speech, such as web-based discussion sites, blogs, and consumeroriented online communities. These diverse platforms and options offer more opportunities for online consumers to interact with other like-minded consumers and reduce information asymmetry. Second, these service providers should update and make appropriate transaction rules to exercise the legitimate power for online consumers through capturing consumers' needs and potential legal rights in the name of protecting individual consumers' rights (Kucuk, 2008).

The significant relationships between PCV and emotions suggest that online sellers should pay attention not only to transactional outcomes but to customer relationship concerns during the recovery process. To prevent consumers from getting dissatisfied, sellers need to ensure the fairness of recovery outcomes (transactional contract) such as the amount of refund, the shipping schedule, quality, and correctness of the exchange product (distributive justice). Additionally, to mitigate customers' anger, this study suggests that sellers should strengthen customer relationships during recovery process by reassessing the fairness and appropriateness of existing recovery procedures (procedural justice) as well as the attitude and quality of customerseller communications (interpersonal and informational justice). For example, seller should respond to consumers' complaints or questions in a timely manner; have fair policies to handle problems or disputes; treat consumers with respect during the interactions; and provide relevant information to meet consumers' specific needs. Although the concept of relational contract seems more abstract than that of transactional contract for sellers, the good news is that fair procedures and interactions can lower the economic cost of complaining and thus reduce the compensation needed to achieve distributive justice (Tax and Brown, 1998).

\section{Limitations and Future Research}

This study has several limitations that create some opportunities for future research. First, the data were collected from the single auction website, Yahoo-Kimo, the largest online auction marketplace in Taiwan. Whether our findings can be generalized to other auction websites remains unclear. Further verifying the generalizability of the 
proposed model in other online marketplaces is highly encouraged to reinforce the study's external validity. Second, the results may have been impacted by self-selection bias. Our sample consisted only online consumers with service recovery experiences in YahooKimo's auctions. Individuals who had already ceased to participate in Yahoo-Kimo's auctions might have different perceptions about the influence of the underlying constructs in this study. Therefore, this study will require additional data for further research before it could be generalized to nonparticipants, and disaffected participants.

\section{References}

Amichai-Hamburger, Y. (2008). "Internet Empowerment," Computers in Human Behavior, 24, pp. 1773-1775.

Anderson, E.W. (1998). "Customer Satisfaction and Word-of-Mouth," Journal of Service Research, 1(1), pp. 1-14.

Anderson, J.C. and Gerbing, D.W. (1988). "Structural Equation Modeling in Practice: A Review and Recommended Two-step Approach," Psychological Bulletin, 103(3), pp. 411-423.

Anderson, M.L. and Taylor, H.F. (2005). Sociology: Understanding a Diverse Society. Wadsworth Publishing: East Windsor, CT.

Andersson, L.M. (1996). "Employee Cynicism: An Examination Using a Contract Violation Framework," Human Relations, 49(11), pp. 1395-1418.

Ashforth, B.E., Tomiuk, M.A. and Kulik, C.T. (2008). "Doing Emotion in Service Encounters: Service Agents' Perceptions of Emotional Labor and Emotional Contagion," in Cooper, C.L. (ed.), Research Companion to Emotions in Organizations, Edward Elgar: Cheltenham, UK.

Aquino, K., Griffeth, R.W., Allen, D.G. and Hom, P.W. (1997). "Integrating justice constructs into the turnover process: A test of a referent cognitions model," Academy of Management Journal, 40(5), pp. 1208-1227.

Bagozzi, R. (1986). Principles of Marketing Management. Science Research Associates, Inc.: Chicago.

Barclay, L.J., Skarlicki, D.P. and Pugh, S.D. (2005). "Exploring the Role of Emotions in Injustice Perceptions and Retaliation." Journal of Applied Psychology, 90 (4), pp. 629-643.

Barlow, J. and Møller, C. (2009). A Complaint Is a Gift: Recovering Customer Loyalty When Things Go Wrong. Berrett-Koehler: San Francisco, CA.

Berry, L.L. (1995). On Great Service. Free Press: New York.

Bitner, M.J., Booms, B.H. and Tetreault, M.S. (1990). "The Service Encounter: Diagnosing Favorable and Unfavorable Incidents," Journal of Marketing, 54, pp. 71-84.

Blodgett, J.G., Hill, D.J. and Tax, S.S. (1997). "The Effects of Distributive, Procedural, and Interactional Justice on Postcomplaint Behaviour," Journal of Retailing, 73(2), pp. 185-210.

Bougie, R., Pieters, R. and Zeelenberg, M. (2003). "Angry Customers Don't Come Back, They Get Back: The Experience and Behavioral Implications of Anger and Dissatisfaction in Services," Journal of the Academy of Marketing Science, 31(4), pp. 377-393.

Brown, S., Cowles, D. and Tuten, T. (1996). "Service Recovery: Its Value and Limitations as a Real Strategy," International Journal of Service Industry Management, 7(5), pp. 32-46.

Campbell, C.R. and Martinko, M.J. (1998). "An Integrative Attributional Perspective of Empowerment and Learned Helplessness: A Multimethod Field 
Study," Journal of Management, 24(2), pp. 173-200.

Carr, C.L. (2007). "The FAIRSERV Model: Consumer Reactions to Services Based on a Multidimensional Evaluation of Service Fairness," Decision Sciences, 38(1), pp. 107-130.

Chebat, J.-C. and Slusarczyk, W. (2005). "How Emotions Mediate the Effects of Perceived Justice on Loyalty in Service Recovery Situations: An Empirical Study," Journal of Business Research, 58, pp. 664-673.

Chin, W.W. (1998). "The Partial Least Squares Approach to Structural Equation Modeling," in Marcoulides, G.A. (ed.), Modern Methods for Business Research, Lawrence Erlbaum Associates: Mahwah.

Chin, W.W., Marcolin, B.L. and Newsted, P.R. (2003). "A Partial Least Squares Latent Variable Modeling Approach for Measuring Interaction Effects: Results from a Monte Carlo Simulation Study and Voice Mail Emotion/Adoption Study," Information Systems Research, 14(2), pp. 189-217.

Colquitt, J.A. (2001). "On the Dimensionality of Organizational Justice: A Construct Validation of A Measure," Journal of Applied Psychology, 86(3), pp. 386-400.

Conway, N. and Briner, R.B. (2005). Understanding Psychological Contracts at Work: A Critical Evaluation of Theory and Research. Oxford University Press: Oxford.

Cullinane, N. and Dundon, T. (2006). "The Psychological Contract: A Critical Review," International Journal of Management Reviews, 8(2), pp. 113129.

Denegri-Knott, J., Zwick, D. and Schroeder, J.E. (2006). "Mapping Consumer Power: An Integrative Framework for Marketing and Consumer Research," European Journal of Marketing, 40 (9/10), pp. 950971.
DeWitt, D.T. and Brady, M.K. (2003). "Rethinking Service Recovery Strategies," Journal of Service Research, 6(2), pp. 193-207.

Downton, S. (2002). "Measurements to Achieve Customer Focus," Retrieved from

http://www.downtonconsulting.com/articl es/Customers/measurements on August 12, 2013.

Duhachek, A. (2005). "Coping: A Multidimensional, Hierarchical Framework of Responses to Stressful Consumption Episodes," Journal of Consumer Research, 32, pp. 41-53.

Dwyer, F.R., Schurr, P.H. and Oh, S. (1987). "Developing Buyer-Seller Relationships," Journal of Marketing, 51, pp. 11-27.

Fang, Y.H. (2012). "Does Online Interactivity Matter? Exploring the Role of Online Interactivity Strategies in Consumer Decision Making," Computers in Human Behavior, 28, pp. 1790-1804.

Fang, Y.H. and Chiu, C.M. (2010). "In justice we trust: Exploring knowledge-sharing continuance intentions in virtual communities of practice," Computers in Human Behavior, 26(2), pp. 235-246.

Featherman, M. and Fuller, M. (2003). "Applying TAM to E-services Adoption: The Moderating Role of Perceived Risk," Proceedings of the 36th Hawaii International Conference on System Sciences, Hawaii, USA.

Fitzsimmons, J.A. and Fitzsimmons, M.J. (2001). Service Management: Operations, Strategy, and Information Technology. McGraw Hill: New York.

Folkes, V.S., Koletsky, S. and Graham, J.L. (1987). "A Field Study of Causal Inferences and Consumer Reaction: The View from the Airport," Journal of Consumer Research, 13, pp. 534-539.

Fornell, C. and Larcker, D.F. (1981). "Evaluating Structural Equation Models 
with Unobservable and Measurement Error," Journal of Marketing Research, 18(1), pp. 39-50.

French, J. and Raven, B. (1959). "The Basis of Social Power," in Cartwright, D. (ed.), Studies in Social Power, University of Michigan: Ann Arbor.

Friedman, M. (1985). "Consumer Boycotts in the United States, 1970-1980: Contemporary Events in Historical Perspective," Journal of Consumer Affairs, 19, pp. 96-117.

Grégoire, Y. and Fisher, R.J. (2008). "Customer Betrayal and Retaliation: When Your Best Customers Become Your Worst Enemies," Journal of the Academy Marking Science, 36, pp. 247-261.

Guest, D.E. and Conway, N. (2002). "Communicating the Psychological Contract: An Employer Perspective," Human Resource Management Journal, 12, pp. 22-38.

Harrison, T., Waite, K. and Hunter, G.L. (2006). "The Internet, Information and Empowerment," European Journal of Marketing, 40(9/10), pp. 972-993.

Hui, M.K. and Bateson, J.E.G. (1991). "Perceived Control and the Effects of Crowding and Consumer Choice on the Service Experience," Journal of Consumer Research, 18, pp. 174-184.

Huefner, J.C. and Hunt, H.K. (2000). "Consumer Retaliation as A Response to Dissatisfaction," Journal of Consumer Satisfaction, Dissatisfaction and Complaining Behavior, 13, pp. 61-82.

Keaveney, S.M. (1995). "Customer Switching Behavior in Service Industries: An Exploratory Study," Journal of Marketing, 59, pp. 71-82.

Keil, M., Tan, B. C. Y., Wei, K. K. and Saarinen, T. (2000). "A Cross-Cultural Study on Escalation of Commitment
Behavior in Software Projects," MIS Quarterly, 24, pp. 299-325.

Kemper, T.D. (1987). "How many emotions are there? Wedding the social and the autonomic components," The American Journal of Sociology, 93, pp. 263-289.

Kickul, J. and Lester, S. W. (2001). "Broken promises: Equity sensitivity as a moderator between psychological contract breach and employee attitudes and behavior," Journal of business and psychology, 16(2), pp. 191-217.

Klein, J.G., Smith, N.C. and John, A. (2004). "Why We Boycott: Consumer Motivations for Boycott Participation," Journal of Marketing, 68, pp. 92-109.

Koufaris, M. (2002). "Applying the Technology Acceptance Model and Flow Theory to Online Consumer Behavior," Information Systems Research, 13(2), pp. 205-223.

Kucuk, S.U. (2008). "Consumer Exit, Voice, and Power on the Internet," Journal of Research for Consumers, 15, pp. 1-13.

Kuo, Y.F. and Wu, C.M. (2012). "Satisfaction and post-purchase intentions with service recovery of online shopping websites: Perspectives on perceived justice and emotions," International Journal of Information Management, 32(2), pp. 127-138.

Langer, E.J. and Judith, R. (1976). "The effects of choice and enhanced personal responsibility for the aged: $A$ field experiment in an Institutional setting," Journal of Personality and Social Psychology, 34, pp. 191-198.

Lazarus, R.S. (1991). Emotion and Adaptation. Oxford University Press: Oxford, UK.

Lazarus, R.S. and Cohen-Charash, Y. (2004). "Discrete Emotions in Organizational Life," In Payne, R.L. and Cooper, C.L. (Eds.), Emotions at Work: Theory, Research and Applications for 
Management. John Wiley and Sons: Chichester, UK.

Lazarus, R.S. and Folkman, S. (1984). Stress, Appraisal, and Coping. Springer: New York.

Li, C.Y., Fang, Y.H., and Wu, B.S. (2013). "Applying Expectation Theory and Justice Theory for Online Service Failure Recovery," Journal of ebusiness, 15(3), pp. 367-388.

Marketing-Management. (2007). "Shop and Compare," Marketing Management, 16(2), p. 7.

Martinko, M.J. and Gardner, W.L. (1987). "The Leader/Member Attribution Process," Academy of Management Review, 12(2), pp. 235-249.

Mavor, K.I., Macleod, C.J., Boal, M.J. and Louis, W.R. (2009). Right-Wing Authoritarianism, Fundamentalism and Prejudice Revisited: Removing Suppression and Statistical Artifact," Personality and Individual Differences, 46, pp. 592-597.

Maxham-III, J.G. and Netemeyer, R.G. (2002). "Modeling Customer Perceptions of Complaint Handling Over Time: The Effects of Perceived Justice on Satisfaction and Intent," Journal of Retailing, 78, pp. 239-252.

McColl-Kennedy, J.R., Patterson, P.G., Smith, A.K. and Brady, M.K. (2009). "Customer Rage Episodes: Emotions, Expressions and Behaviors," Journal of Retailing, 85(2), pp. 222-237.

McCollough, M.A., Berry, L.L. and Yadav, M.S. (2000). "An Empirical Investigation of Customer Satisfaction after Service Failure and Recovery," Journal of Service Research, 3(2), pp. 121-137.

Morrison, E.W. and Robinson, S.L. (1997). "When Employees Feel Betrayed: A Model of How Psychological Contract Violation Develops," Academy of Management Review, 21(1), pp. 226256.
Neal, A.G. and Seeman, M. (1964). "Organizations and Powerlessness: A Test of the Mediation Hypothesis," American Sociological Review, 29(2), pp. 216-226.

Nunziato, C.D. (2000). "Exit, Voice and Values on the Net," Berkeley Technology Law Journal, 15(2), pp. 753-776.

Oliver, R.L. (1997). Satisfaction: A Behavioral Perspective on the Consumer. McGraw-Hill: New York.

Ortiz-de-Guinea, A. and Markus, M.L. (2009). "Why Break the Habit of a Lifetime? Rethinking the Roles of Intention, Habit, and Emotion in Continuing Information Technology Use," MIS Quarterly, 33(3), pp. 433-444.

Pavlou, P.A., and Gefen, D. (2005). "Psychological Contract Violation in Online Marketplaces: Antecedents, Consequences, and Moderating Roles," Information Systems Research, 16(4), pp. 372-399.

Pavlou, P.A., Liang, H. and Xue, Y. (2007). "Understanding and Mitigating Uncertainty in Online Exchange Relationships: A Principal-Agent Perspective," MIS Quarterly, 31(1), pp. 105-136.

Pitt, L.F., Berthon, P., Watson, R.T., and Ewing, M. (2001). "Pricing strategy and the Net", Business Horizons, 44(2), pp. 45-54.

Rezabakhsh, B., Bornemann, D., Hansen, U. and Schrader, U. (2006). "Consumer Power: A Comparison of the Old Economy and the Internet Economy," Journal of Consumer Policy, 29, pp. 336.

Rha, J.-Y. and Widdows, R. (2002). "The Internet and the Consumer: Countervailing Power Revisited," Prometheu, 20, pp. 107-118.

Robertson, N. and Shaw, R.N. (2006). "Conceptualizing the Influence of the 
Self-Service Technology Context on Consumer Voice," Services Marketing Quarterly, 27(2), pp. 33-50.

Roseman, I.J., Wiest, C.M.S. and Swartz, T.S. (1994). "Phenomenology, Behaviors, and Goals Differentiate Discrete Emotions?" Journal of Personality and Social Psychology, 67, pp. 206-211.

Ross, C.E., and Broh, B.A. (2000). "The Roles of Self-Esteem and the Sense of Personal Control in the Academic Achievement Process," Sociology of Education, 73, pp. 270-284.

Rousseau, D.M. (1989). "Psychological and Implied Contracts in Organizations," Employee Responsibilities and Rights Journal, 2(2), pp. 121-139.

Rousseau, D.M. (1995). Psychological Contracts in Organizations. Sage Publications: Thousand Oaks, CA.

Rousseau, D.M. and Ho, V.T. (2000). "Psychological Contract Issues in Compensation," in Rynes, S.L. and Gerhart, B. (eds.), Compensation in Organizations: Current Research and Practice, Jossey-Bass: San Francisco.

Rust, R.T. and Kannan, P.K. (2003). "Eservice: A New Paradigm for Business in the Electronic Environment," Communications of the ACM, 46, pp. 36-42.

Schneider, B. and Bowen, D.E. (1999). "Understanding Customer Delight and Outrage," Sloan Management Review, 41(1), pp. 35-45.

Schoefer, K. and Diamantopoulos, A. (2008). "The Role of Emotions in Translating Perceptions of (In)justice into Postcomplaint Behavioral Responses," Journal of Service Research, 11(1), pp. 91-103.

Sen, S., Gurhan-Canli, Z. and Morwitz, V. (2001). "Withholding Consumption: A Social Dilemma Perspective on Consumer Boycotts," Journal of
Consumer Research, 28(3), pp. 399417.

Shore, L.M. and Tetrick, L.E. (1994). "The Psychological Contract as An Explanatory Framework in the Employment Relationship," in Cooper, C.L. and Rousseau, D.M. (eds.), Trends in Organizational Behavior, John Wiley: New York.

Tax, S.S. and Brown, S.W. (1998). "Recovering and Learning from Service Failure," Sloan Management Review, 40(1), pp. 75-88.

Turnley, W.H. and Feldman, D.C. (2000). "Re-examining the effects of psychological contract violations: unmet expectations and job dissatisfaction as mediators," Journal of organizational behavior, 21(1), pp. 25-42.

Voorhees, C.M., Brady, M.K. and Horowitz, D.M. (2006). "A Voice from the Silent Masses: An Exploratory and Comparative Analysis of Noncomplainers," Journal of the Academy of Marketing Science, 34(4), pp. 514-527.

Wathieu, L., Brenner, L., Carmon, Z., Chattopahyay, A., Wetenbroch, K., Drolet, A., ... \& Wu, G. (2002). Consumer control and empowerment: A primer. Marketing Letters, 13(3), pp. 297-305.

Weary, G., Stanley, M.A. and Harvey, J.H. (1989). Attribution. Springer-Verlag: New York.

Weiner, B. (1986). An Attributional Theory of Motivation and Emotion. SpringerVerlag: New York.

Woodworth, R. S. (1928). Psychologies of 1925. Clark University Press: Worcester.

Zeithaml, V. and Bitner, M.J. (1996). Services Marketing. McGraw-Hill: New York, NY.

Zemke, R. and Bell, C.R. (2000). Knock Your Socks off Service Recovery. Amacom: New York. 


\section{Appendix. A. Questionnaire Items}
Consumer Switching Behaviors (Bougie et al., 2003)
SWT1 When I need to make a purchase, I will not buy from this seller anymore.
SWT2 When I need to make a purchase, this seller is my first choice. (R)
SWT3 I like buying from this seller more than others in this category. (R)
SWT4 To me this seller is the best seller to do business with. (R)
SWT5 I believe this seller is my preferred seller in this category. $(R)$

\section{Electronic Word-of-Mouth (Bougie et al., 2003; Grégoire and Fisher, 2008)}

Through Internet technologies (e.g., email, MSN, blogs, and public forum), ...

WOM1 I spread negative word-of-mouth about the seller.

WOM2 I post negative things about the seller to share my feelings with others.

WOM3 I discourage people to do business with this seller.

WOM4 I share my bad experience to warn other people.

\section{E-Boycott (Grégoire and Fisher, 2008; Klein et al., 2004)}

Through Internet technologies (e.g., email, MSN, blogs, and public forum),

EBO1 I would boycott the seller.

EBO2 I would initiate boycotts against the seller.

EBO3 I would advocate boycotts to get the seller in trouble.

EBO4 I would cause inconvenience to the seller through boycotts.

EBO5 I would punish the seller through boycotts.

\section{Distributive Injustice (Colquitt, 2001) \\ Regarding the outcome of service recovery, \\ DJ1 Does your outcome reflect the effort you put into resolving the complaint? (R) \\ DJ2 Is your outcome appropriate for the process you have completed (e.g., the inconvenience caused by the problem)? (R) \\ DJ3 Is your outcome (e.g., recovery outcome) similar to your expectations of it? (R) \\ DJ4 Is your outcome justified, given the time, money, and hassle? (R)}

Procedural Injustice (Colquitt, 2001)

Regarding the procedural of service recovery,

PJ1 Have those procedures been free of bias? $(R)$

$\mathrm{PJ} 2 \quad$ Have those procedures been based on accurate information? (R)

PJ3 Have those procedures upheld ethical and moral standards? $(R)$

PJ4 Has the seller communicated details in a timely manner? (R)

Interpersonal Injustice (Colquitt, 2001)

During the process of service recovery, 
Pacific Asia Journal of the Association for Information Systems, Vol. 6, Iss. 1 [2014], Art. 4

Exploring Online Double Deviation Effect from Psychological Contract Violation / Fang \& Chiu

IPJ1 The seller treated you in a polite manner? (R)

IPJ2 The seller treated you with dignity? (R)

IPJ3 The seller treated you with respect? (R)

IPJ4 The seller refrained from improper remarks or comments? (R)

Informational Injustice (Colquitt, 2001)

During the process of service recovery,

IFJ1 Has the seller been candid in communications with you? (R)

IFJ2 Has the seller explained the procedure thoroughly? (R)

IFJ3 Were the seller explanations regarding the procedure reasonable? $(R)$

IFJ4 Has the seller seemed to tailor communications to individuals' specific needs? (R)

\begin{tabular}{|c|c|}
\hline \multicolumn{2}{|c|}{ Dissatisfaction (Bougie et al., 2003) } \\
\hline \multicolumn{2}{|c|}{ Through the service recovery, I felt... } \\
\hline DIS1 & ... dissatisfied \\
\hline DIS2 & ... displeased \\
\hline DIS3 & ... discontented \\
\hline \multicolumn{2}{|c|}{ Anger (Bougie et al., 2003) } \\
\hline \multicolumn{2}{|c|}{ Through the service recovery, I felt... } \\
\hline ANG1 & ... outraged \\
\hline ANG2 & ... resentful \\
\hline ANG3 & ... angry \\
\hline \multicolumn{2}{|c|}{ Perceived Power (Klein et al., 2004; Sen et al., 2001) } \\
\hline PP1 & I feel as though I can't make a difference. (R) \\
\hline PP2 & Persons like my-self have little chance of influencing sellers' decision making. (R) \\
\hline PP3 & $\begin{array}{l}\text { Since I cannot have significant effect on affecting the seller, it doesn't make any } \\
\text { difference what I do. }(R)\end{array}$ \\
\hline \multicolumn{2}{|c|}{ Perceived Consumer Empowerment (Hunter and Garnefeld, 2008) } \\
\hline PCE1 & In my dealings with this seller, I feel I am in control. \\
\hline PCE2 & My ability to influence the services and behaviors of this seller is beneficial to me. \\
\hline PCE3 & I feel good because of my ability to against the seller. \\
\hline PCE4 & My influence over this seller has increased relative to the past. \\
\hline
\end{tabular}

R: Reverse Coded 


\section{About Authors}

Yu-Hui Fang is an Assistant Professor in the Department of Accounting at the Tamkang University, Taiwan (ROC). She gained her $\mathrm{PhD}$ degree in Information Management from National Central University and her Masters degree in Accounting from University of Houston. Her research interests include ecommerce, service management, and knowledge management. She has won the best paper award at the 2009 Pacific Asia Conference on Information Systems (PACIS) and at the 2009 e-Case International Conference. Her research has appeared in Information Systems Journal, International journal of Electronic Commerce, Computers in Human Behavior, Internet Research, Journal of $\mathrm{E}$-Business, Online Information Review, and others.
Chao-Min Chiu is a Professor in the Department of Information Management at the National Sun Yat-sen University, Taiwan (ROC). He holds a PhD in Management from the Rutgers University. His research interests include electronic commerce, virtual communities, and knowledge management. His research has appeared in Information Systems Journal, Decision Support Systems, Information \& Management, International Journal of Human-Computer Studies, Computers \& Education, Computers in Human Behavior, Electronic Commerce Research and Applications, Behaviour \& Information Technology, Information and Software Technology, Information Technology and Management, and others. 